\title{
Stimulant drug effects on touchscreen automated paired-associates learning (PAL) in rats
}

\author{
Corinna Roschlau, Angeline Votteler, and Wolfgang Hauber
}

Department Animal Physiology, University of Stuttgart, D-70550 Stuttgart, Germany

\begin{abstract}
Here we tested in rats effects of the procognitive drugs modafinil and methylphenidate on post-acquisition performance in an object-location paired-associates learning (PAL) task. Modafinil (32; $64 \mathrm{mg} / \mathrm{kg}$ ) was without effect, while higher (9 mg/ $\mathrm{kg}$ ) but not lower $(4.5 \mathrm{mg} / \mathrm{kg}$ ) doses of methylphenidate impaired PAL performance. Likewise, higher but not lower doses of amphetamine $(0.4 ; 0.8 \mathrm{mg} / \mathrm{kg})$ and MK-801 $(0.08 ; 0.12 \mathrm{mg} / \mathrm{kg})$ decreased PAL performance. Impaired PAL performance induced by methylphenidate, amphetamine, and MK801 most likely reflects compromised cognitive function, e.g., retrieval of learned paired associates. Our data suggest that stimulant drugs such as methylphenidate and modafinil might not facilitate performance in hippocampus-related cognitive tasks.
\end{abstract}

[Supplemental material is available for this article.]

Touchscreen equipped operant boxes represent a powerful tool to study cognition in rats. This methodology provides superior translational potential because a number of different cognitive tasks can be run that mirror touchscreen methods being part of the Cambridge Neuropsychological Test Automated Battery (CANTAB) used to test human subjects. For instance, the pairedassociates learning task (PAL) allows to investigate learning of object-location associations in rodents and humans (Horner et al. 2013; Mar et al. 2013; Talpos and Steckler 2013; Josey and Brigman 2015). In rats, post-acquisition performance on the PAL task is sensitive to hippocampal dysfunction. For instance, intrahippocampal microinfusions of lidocaine or NMDA and AMPA receptor antagonists impaired PAL performance in animals that acquired the task before (Talpos et al. 2009). Likewise, in mice, post-acquisition intrahippocampal microinfusions of muscimol impaired PAL performance (Kim et al. 2015). In humans, PAL task performance is predictive of the conversion from mild cognitive dysfunction to Alzheimer's disease (Blackwell et al. 2004). Furthermore, in mild cognitive impairment, PAL performance was correlated with hippocampal volume (Keri et al. 2012).

To date, little is known about effects of procognitive drugs on PAL performance. The few available data show that, in mice, the cholinesterase inhibitor donezepil $(0.3 \mathrm{mg} / \mathrm{kg}$, i.p. $)$ facilitated PAL performance (Bartko et al. 2011). In contrast, the effects of two other prominent procognitive drugs, methylphenidate and modafinil, in PAL have not been tested yet. Modafinil facilitated performance in a number of rodent cognitive tasks (Beracochea et al. 2001, 2002, 2003; Shuman et al. 2009), e.g., enhanced visual discrimination and visual sustained attention (Morgan et al. 2007). Likewise, methylphenidate improved acquisition and retention of spatial memory in maze tasks (Carmack et al. 2014). Both drugs seem to be used as cognitive enhancers for nonmedical purposes (McCabe et al. 2005). However, for both drugs, evidence in favor of cognitive enhancement in humans is mixed (Repantis et al. 2010). For instance, in healthy individuals, methylphenidate and modafinil did not improve PAL (Turner et al. 2003a; Muller et al. 2013).

Here we tested the effects of systemic methylphenidate and modafinil on post-acquisition PAL performance of rats. As both

\section{Corresponding author: hauber@bio.uni-stuttgart.de}

Article is online at http://www.learnmem.org/cgi/doi/10.1101//m.040345.115. drugs failed to improve PAL performance in humans we hypothesize that they would not improve PAL performance in rats. For validation, we included the indirect dopamine agonist amphetamine and the NMDA receptor antagonist MK801, drugs with known effects on PAL performance (Talpos et al. 2014, 2015). Here we show that the higher but not lower doses of methylphenidate, amphetamine, and MK-801 impaired cognitive performance in the PAL task while modafinil at both doses tested was without effect.

All animal experiments were conducted according to the German law of animal protection and approved by the proper authorities. Male Lister Hooded rats (Charles River Laboratories, UK) were used weighting between 230 and $270 \mathrm{~g}$ at the beginning of the experiment. Details on housing conditions are given in the Supplemental Material. Operant boxes (Med Associates; $31.8 \times$ $25.4 \times 26.7 \mathrm{~cm}$ ) were used with one end of the chamber equipped with a touch-sensitive, flat-screen LCD monitor equipped with an infrared sensor (see Supplemental Material for details on the touch screen box configuration). Animals were trained and tested on the dPAL task ("different paired-associate learning") according to a protocol by Talpos et al. (2009). In brief, the PAL task demands learning that a particular object, i.e., one out of three symbols, is only correct in a particular location, i.e., one out of three positions on the touchscreen. On a given trial, two symbols are displayed, one in its correct, another one in an incorrect position, and the rat has to respond to the symbol in the correct position (Supplemental Fig. S1). For details of the habituation, pretraining, and training protocol see Supplemental Material. Amphetamine (Sigma) was dissolved in saline $(0.9 \% \mathrm{NaCl}$, Braun Melsungen), modafinil ((2-(diphenylmetyhl)sulfinyl)acetamide (Sequoia) was dissolved in $1 \% \mathrm{w} / \mathrm{v}$ methylcellulose (Sigma) in saline, methylphenidate (Sigma) was dissolved in saline, MK-801 was dissolved in saline. All drugs were administered i.p. $30 \mathrm{~min}$ prior behavioral testing. IP injections of respective vehicles served as controls. For all experiments, the same group of animals was used $(n=6)$. All experiments used a within-group design in which each rat

\footnotetext{
(C) 2016 Roschlau et al. This article is distributed exclusively by Cold Spring Harbor Laboratory Press for the first 12 months after the full-issue publication date (see http://learnmem.cshlp.org/site/misc/terms.xhtml). After 12 months, it is available under a Creative Commons License (AttributionNonCommercial 4.0 International), as described at http://creativecommons. org/licenses/by-nc/4.0/.
} 
received all drugs and respective vehicle treatments with one treatment on one test day per week. Baseline training sessions without drug administration were conducted $4 \mathrm{~d}$ per week. The order of drug testing was as follows: amphetamine, methylphenidate, modafinil, MK-801. Drugs were administered using a withinsubject cross-over design, i.e., half of the animals received drug or vehicle on the test day in week 1 ; this assignment was reversed on the test day in week 2. Percent correct, response latencies (time from symbol activation on the monitor to the response at the monitor), and magazine latencies (time from the response at the monitor until magazine entry) are given as means \pm standard error of the mean (SEM). Data from each drug dose and respective vehicle control were subjected to a paired $t$-test.

Administration of the lower dose of amphetamine $(0.4 \mathrm{mg} /$ $\mathrm{kg})$ tended to reduce the number of correct responses $\left(t_{5}=2.23\right.$, $P=0.07)$, decreased response latencies $\left(t_{5}=3.24, P<0.05\right)$ but left unchanged magazine latencies $\left(t_{5}=0.90\right.$, n.s. $)$. In contrast, the higher dose of amphetamine $(0.8 \mathrm{mg} / \mathrm{kg})$ significantly reduced the number of correct responses $\left(t_{5}=2.87, P<0.05\right)$, but did not alter response latencies $\left(t_{5}=0.03\right.$, n.s.) or magazine latencies $\left(t_{5}=1.63\right.$, n.s.) (Fig. 1$)$. No effect of amphetamine as well as all other drugs tested was ever seen on the number of trials completed, therefore, these data are not presented. Methylphenidate at $4.5 \mathrm{mg} / \mathrm{kg}$ did not change the number of correct responses $\left(t_{5}=0.16\right.$, n.s. $)$ and left unaffected response latencies $\left(t_{5}=1.49\right.$, n.s.) and magazine latencies ( $t_{5}=1.63$, n.s.) (Fig. 2). In contrast, methylphenidate at $9 \mathrm{mg} / \mathrm{kg}$ reduced the number of correct responses $\left(t_{5}=3.56, P<0.05\right)$ and decreased response latencies $\left(t_{5}=3.35, P<0.05\right)$ but not magazine latencies $\left(t_{5}=2.79\right.$, n.s. $)$ (Fig. 2). Modafinil at $32 \mathrm{mg} / \mathrm{kg}$ did not alter the number of correct responses $\left(t_{5}=1.48\right.$, n.s. $)$, response latencies $\left(t_{5}=0.05\right.$, n.s. $)$ and magazine latencies $\left(t_{5}=0.52\right.$, n.s.). Likewise, modafinil at 64 $\mathrm{mg} / \mathrm{kg}$ had no effects on the number of correct responses $\left(t_{5}=\right.$ 1.76 , n.s.), response latencies $\left(t_{5}=1.17\right.$, n.s.) and magazine latencies $\left(t_{5}=0.06\right.$, n.s.) (Fig. 3). Administration of the lower dose of MK-801 $(0.8 \mathrm{mg} / \mathrm{kg})$ did not alter the number of correct responses $\left(t_{5}=0.69\right.$, n.s. $)$, response latencies $\left(t_{5}=2.11\right.$, n.s. $)$, and magazine latencies $\left(t_{5}=1.73\right.$, n.s.). However, the higher dose of MK-801 $(1.2 \mathrm{mg} / \mathrm{kg})$ reduced the number of correct responses $\left(t_{5}=2.61\right.$, $P<0.05)$ but did not alter response latencies $\left(t_{5}=1.96\right.$, n.s. $)$ and magazine latencies ( $t_{5}=0.52$, n.s.) (Supplemental Fig. S2).

Here we show that amphetamine at $0.8 \mathrm{mg} / \mathrm{kg}$ markedly reduced correct choices but not response and magazine latencies. Likewise, Talpos et al. (2014) revealed that amphetamine (0.5, $0.75 \mathrm{mg} / \mathrm{kg}$ ) significantly reduced correct choices in PAL without influencing response latencies. The findings by Talpos et al. (2014) and our findings imply that impaired choice accuracy seen here may not be secondary to amphetamine-induced behavioral activation or enhanced impulsivity (Cole and Robbins 1987), effects that might have altered response or magazine latencies. Of note, in a touchscreen-based complex visual discrimination task that, by using morphed stimulus pairs, involved increasing levels of perceptual demands, amphetamine dose-dependently impaired choice accuracy (Talpos et al. 2012). Of note, there was no dose $\times$ perceptual complexity interaction. The failure to detect such an interaction strongly suggests that amphetamine did not compromise visual discrimination. Collectively, these findings indicate that the effects of amphetamine in the PAL task used here may not reflect disrupted visual discrimination. Alternatively, amphetamine could have interfered with memory retrieval, however, the few available studies in humans and laboratory animals gave mixed results. For instance, in rats tested in a radial maze task, amphetamine $(0.25 ; 0.5 \mathrm{mg} / \mathrm{kg})$ facilitated retrieval of spatial information (Sara and Deweer 1982). In contrast, in humans, moderate doses of amphetamine that enhanced memory encoding and consolidation, increased retrieval errors in an episodic mem-

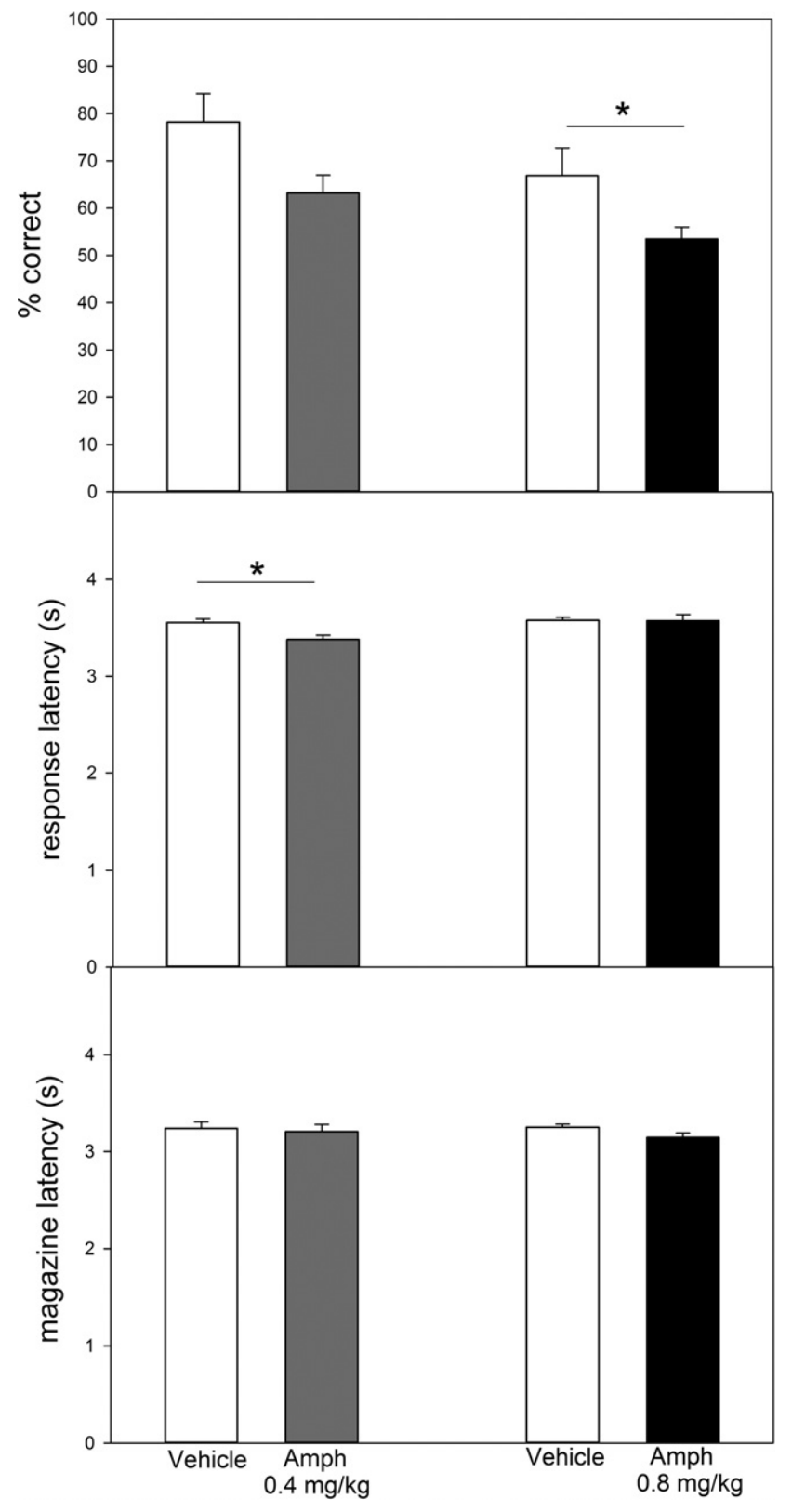

Figure 1. Effects of amphetamine $(0.4,0.8 \mathrm{mg} / \mathrm{kg})$ on PAL performance. Percent correct responses, response latencies and magazine latencies are given as means \pm SEM. The lower drug dose tended to reduce $\%$ correct responses $(P=0.07$, $t$-test), while the higher dose significantly decreased \% correct responses $\left(\left(^{*}\right) P<0.05\right.$, paired $t$-test). No other significant effects were detected.

ory task involving picture stimuli (Ballard et al. 2014). Thus, it appears that, depending on the type of information, acute amphetamine can impair or facilitate retrieval. Remarkably, chronic amphetamine user's display pronounced impairments in CANTAB including PAL that can persist after several years of drug abstinence and may reflect neuropathology in frontal and temporal cortices (Ersche et al. 2006). It is well known that amphetamine can increase extracellular catecholamines in many brain areas including the hippocampus (Kuczenski and Segal 1997; Borgkvist et al. 2012). Remarkably, glucocorticoids, by promoting the release and/or blocking the reuptake of noradrenaline, can impair retrieval of hippocampus-dependent 


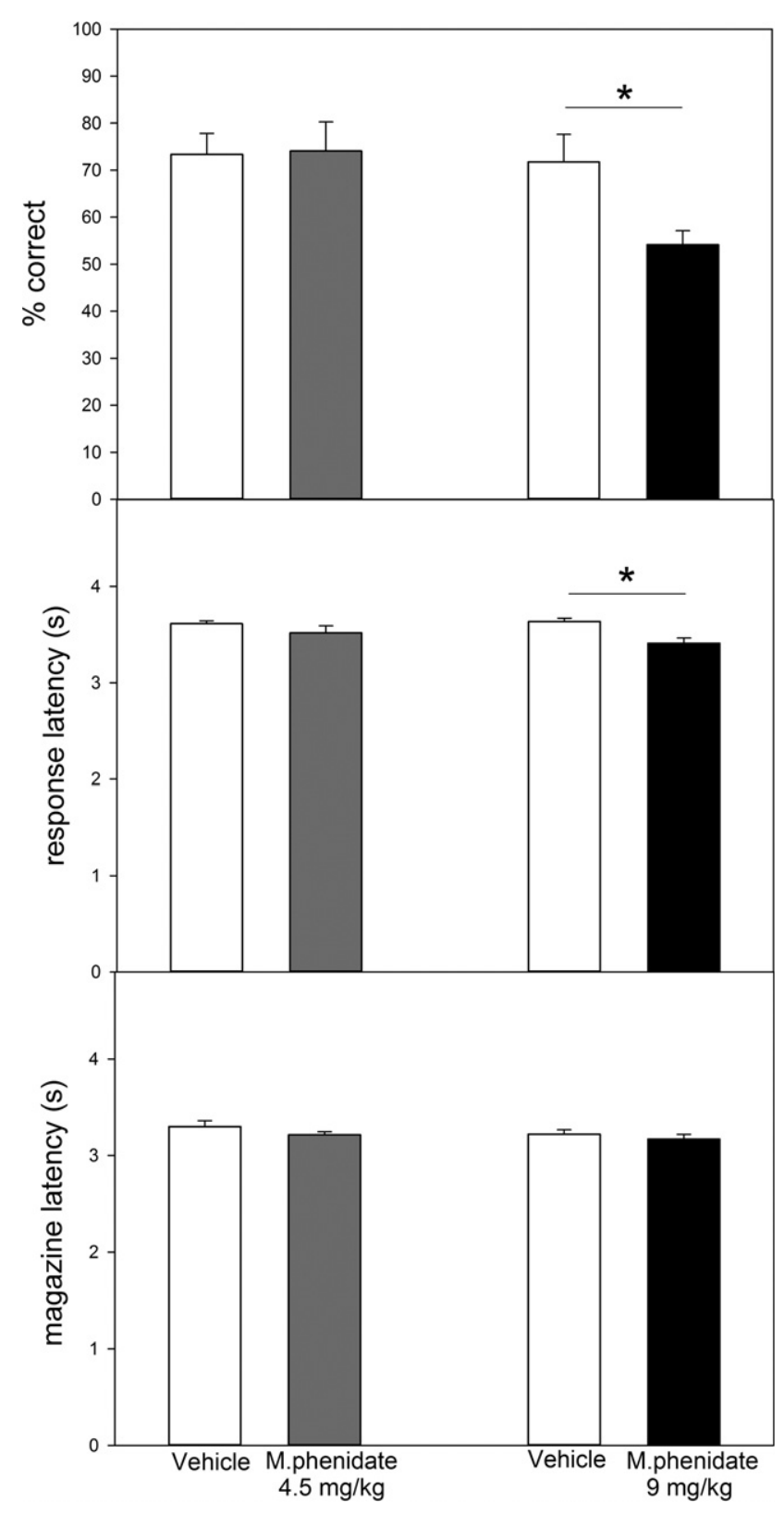

Figure 2. Effects of methylphenidate $(4.5,9.0 \mathrm{mg} / \mathrm{kg})$ on PAL performance. Percent correct responses, response latencies and magazine latencies are given as means \pm SEM. The higher drug dose significantly decreased \% correct responses and response latencies $\left(\left(^{*}\right) P<0.05\right.$, paired $t$-test). No other significant effects were detected.

memory (de Quervain et al. 2007; Schutsky et al. 2011). Thus, an amphetamine-induced increase of hippocampal noradrenaline efflux could provide one mechanism to account for reduced choice accuracy in PAL seen here. Of course, amphetamine effects in PAL could involve actions in other brain areas as well, however, causal evidence for a role of, for instance, the prefrontal cortex to support PAL is missing.

Results further demonstrate that the higher $(9 \mathrm{mg} / \mathrm{kg})$ but not lower dose $(4.5 \mathrm{mg} / \mathrm{kg})$ of methylphenidate markedly reduced correct choices and response latencies. Likewise, in a touchscreenbased visual discrimination task, methylphenidate at higher doses $(\geq 10 \mathrm{mg} / \mathrm{kg}$ ) reduced performance and response speed (Galizio et al. 2009). As we observed no changes in magazine latencies and no correlation between choice accuracy and response latencies in methylphenidate-treated animals, it is unlikely that impaired choice accuracy may directly result from methylphenidate-induced behavioral activation or impulsivity (Milstein et al. 2010; Sommer et al. 2014). Furthermore, as this drug decreased rather than increased response latency, an impaired visual discrimination seems unlikely. Hence, reduced PAL performance under methylphenidate $(9 \mathrm{mg} / \mathrm{kg})$ may not reflect impaired visual discrimination or sustained attention.

Of note, there is evidence that methylphenidate facilitates memory for aversive events (Bethancourt et al. 2009) and can improve spatial learning and memory retrieval in a radial maze task (Zhu et al. 2007, but see Rostron et al. 2013). Interestingly, methylphenidate was also able to compromise object recognition memory (Heyser et al. 2004). Remarkably, electrophysiological studies in vitro revealed that methylphenidate amplifies hippocampal long-term potentiation as well as long-term depression, findings that could explain why methylphenidate was able both to improve and impair learning and memory (Dommett et al. 2008). Here, we found no evidence in favor of enhanced memory retrieval under methylphenidate. Rather, methylphenidate at the higher dose impaired PAL performance. Yet, respective comparisons across studies are limited by the fact that spatial tasks such as PAL and radial maze tasks may involve hippocampal processing but could differ in terms of task complexity or spatial strategies to solve the task.

As methylphenidate, like amphetamine, amplified catecholamine release in numerous brain areas including the hippocampus (Kuczenski and Segal 1997; Borgkvist et al. 2012), we speculate that, as discussed above for amphetamine, an enhanced hippocampal noradrenaline efflux could provide one neurochemical mechanism through which methylphenidate impaired PAL performance. In contrast, the lower dose of methylphenidate did not modify PAL performance. In line with this latter finding, studies on elderly volunteers revealed that low to intermediate clinical doses of methylphenidate $(20,40 \mathrm{mg})$ failed to alter PAL performance (Turner et al. 2003b).

Modafinil did not affect correct choices in PAL as well as response and magazine latencies. As the drug doses used here (32, $64 \mathrm{mg} / \mathrm{kg}$ ) were behaviorally active in various cognitive tasks for rats (Minzenberg and Carter 2008), inappropriate dosing might not account for negative results. Morgan et al. (2007) examined the effects of modafinil $(8-64 \mathrm{mg} / \mathrm{kg})$ in intact rats on visual discrimination and visual sustained attention and were able to show that this drug enhanced sustained attention, i.e., increased accuracy to respond to light emitting diodes in a dose- and delaydependent manner. Thus, the failure to detect PAL effects suggests that an enhanced sustained attention under modafinil as such may be not sufficient to facilitate PAL performance. However, in intact rats that performed the five-choice serial reaction time task, modafinil (32-128 mg/kg) did not improve attention measures (Waters et al. 2005). Likewise, in rats tested in a signal-stop task, modafinil (3-100 mg/kg) did not alter attention (Eagle et al. 2007). Thus, the extent to which modafinil can influence attentional processes and the relevance of such effects in the context of PAL performance remains questionable. Previous studies using an object recognition task showed that modafinil recovered recognition memory in memory-impaired rats, but did not improve memory consolidation and retrieval in naïve rats (Garcia et al. 2013), a finding that is consistent with our negative results in naïve rats. Likewise, in healthy humans, modafinil did not alter performance in PAL (Turner et al. 2003a; Muller et al. 2013).

The NMDA receptor antagonist MK-801 at $0.12 \mathrm{mg} / \mathrm{kg}$ but not $0.08 \mathrm{mg} / \mathrm{kg}$ significantly reduced choice accuracy without concomitant effects on response and magazine latencies suggesting that impaired PAL performance might not be related to drug-induced behavioral activation (Murschall and Hauber 


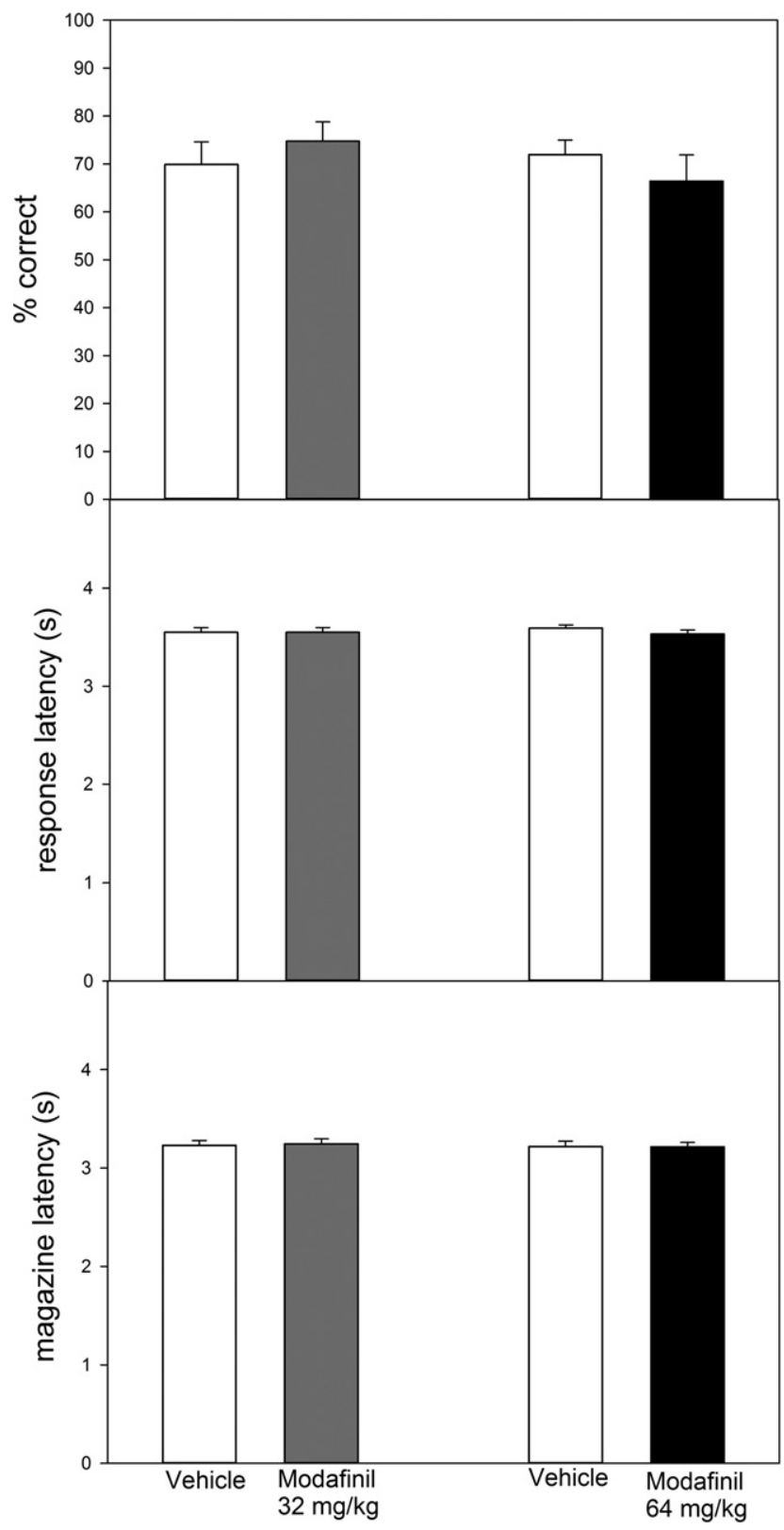

Figure 3. Effects of modafinil $(32,64 \mathrm{mg} / \mathrm{kg})$ on PAL performance. Percent correct responses, response latencies and magazine latencies are given as means \pm SEM. Modafinil had no significant effects on either measure.

2005). A recent study demonstrated that MK801 at $0.075 \mathrm{mg} / \mathrm{kg}$ markedly reduced choice accuracy and increased response and magazine latencies in PAL (Talpos et al. 2015). The reasons for these discrepancies are elusive. Furthermore, the NMDA receptor antagonist PCP reduced accuracy of rats in PAL (Talpos et al. 2014). In contrast, the NMDA receptor antagonist ketamine, for unknown reasons, did not affect PAL performance in rats (Talpos et al. 2014) but in subhuman primates (Taffe et al. 2002), while in humans the effects of NMDA receptor antagonists have not yet been tested. Previous studies using a related touchscreen-based simple visual discrimination task demonstrate that MK801 at $0.1 \mathrm{mg} / \mathrm{kg}$ but at not lower doses reduced choice accuracy and increased response and magazine latencies (Talpos et al. 2012). These findings point to the possibility that MK801 effects on choice accuracy in this simple visual discrimination task could be secondary to nonspecific drug effects. However, in the complex version of the touchscreen-based visual discrimination task that involves morphed stimulus pairs, MK801, like amphetamine, dose-dependently impaired choice accuracy. However, there was no dose $\times$ perceptual complexity interaction suggesting that MK801 did not affect visual discrimination (Talpos et al. 2012). Of note, in well-trained rats, intrahippocampal microinfusion of MK-801 markedly reduced the number of correct responses in the PAL task used here but not in a simpler PAL task version with lower cognitive but similar perceptual demands (Talpos et al. 2009). Hence, a deficient hippocampal NMDA-receptordependent retrieval of paired associates could account, at least in part, for MK801-induced impaired PAL performance seen here.

Taken together, our results demonstrate that the stimulant drugs methylphenidate and modafinil, shown to have some procognitive effects in rats (Morgan et al. 2007; Carmack et al. 2014), did not enhance performance in PAL, a task that is sensitive to hippocampal dysfunction and may serve as a translational model of PAL in humans. Rather, methylphenidate at a higher dose, like higher doses of amphetamine and MK801, impaired PAL performance most likely by interfering with cognitive functions, e.g., retrieval of learned paired associates, rather than with motor or perceptual functions. The observation that methylphenidate and modafinil failed to improve PAL performance in rats is consistent with reports that these drugs at low to intermediate clinical doses did not facilitate PAL performance in healthy individuals (Muller et al. 2013) and patients with dementia (Dolder et al. 2010).

Together, these findings imply that stimulant drugs such as methylphenidate and modafinil might not facilitate performance in hippocampus-related cognitive tasks. Moreover, it is important to consider procedural differences in rodent und human PAL. For instance, in rat PAL, correct responses in a subset of trials (termed here "unique-configuration trials," i.e., trials 1 and 6; Supplemental Fig. S1, left panel) may rely on correct objectlocation associations (i.e., "flower is always correct on the left position"/trial 1; "airplane is always correct on the right position"/ trial 6). However, correct responses in another subset of trials (termed here "common configuration trials," i.e., trials 2-5; Supplemental Fig. S1, left panel) could also involve an alternative strategy, i.e., conditional rules based on the configuration of both presented objects. Examples for such rules are "if flower is left to spider, respond to flower" (trial 2), or, "if flower is right to spider, respond to spider" (trial 4). Given that animals used differential strategies across these trial categories and unique configuration trials are more complex, then, performance should be inferior in unique relative to common configuration trials. In vehicle-treated animals, a post hoc analysis of correct choices as a function of configuration category provided partial evidence in favor of this notion. Yet, none of the drugs tested here impaired correct choices in unique configuration trials (see Supplemental Material). However, these findings are preliminary because (1) we performed post hoc hypothesis testing, (2) the power of our assessment is limited due to the low number of subjects included, (3) the effect assessment is biased as sample sizes of unique $(n=24)$ versus common $(n=48)$ configuration trials per session ( $n=72$ trials) differed markedly. Future studies should investigate in detail an influence of stimulus configuration on correct responding to clarify whether the rat PAL task assesses object-location learning as tested in the human version. One possibility could be subsequent testing using a variant of the PAL task ("sPAL") that may not be solved with a configural strategy (Horner et al. 2013) but is, however, less sensitive to hippocampal dysfunction (Talpos et al. 2009) and requires relearning. 


\section{Acknowledgments}

We are grateful to Igor Newar for assistance in animal husbandry.

\section{References}

Ballard ME, Gallo DA, de Wit H. 2014. Amphetamine increases errors during episodic memory retrieval. J Clin Psychopharmacol 34: 85-92.

Bartko SJ, Vendrell I, Saksida LM, Bussey TJ. 2011. A computer-automated touchscreen paired-associates learning (PAL) task for mice: impairments following administration of scopolamine or dicyclomine and improvements following donepezil. Psychopharmacology (Berl) 214: 537-548.

Beracochea D, Cagnard B, Celerier A, le Merrer J, Peres M, Pierard C. 2001 First evidence of a delay-dependent working memory-enhancing effect of modafinil in mice. Neuroreport 12: 375-378.

Beracochea D, Celerier A, Borde N, Valleau M, Peres M, Pierard C. 2002. Improvement of learning processes following chronic systemic administration of modafinil in mice. Pharmacol Biochem Behav 73: $723-728$.

Beracochea D, Celerier A, Peres M, Pierard C. 2003. Enhancement of learning processes following an acute modafinil injection in mice. Pharmacol Biochem Behav 76: 473-479.

Bethancourt JA, Camarena ZZ, Britton GB. 2009. Exposure to oral methylphenidate from adolescence through young adulthood produces transient effects on hippocampal-sensitive memory in rats. Behav Brain Res 202: 50-57.

Blackwell AD, Sahakian BJ, Vesey R, Semple JM, Robbins TW, Hodges JR. 2004. Detecting dementia: novel neuropsychological markers of preclinical Alzheimer's disease. Dement Geriatr Cogn Disord 17: 42-48.

Borgkvist A, Malmlof T, Feltmann K, Lindskog M, Schilstrom B. 2012. Dopamine in the hippocampus is cleared by the norepinephrine transporter. Int J Neuropsychopharmacol 15: 531-540.

Carmack SA, Block CL, Howell KK, Anagnostaras SG. 2014 Methylphenidate enhances acquisition and retention of spatial memory. Neurosci Lett 567: 45-50.

Cole BJ, Robbins TW. 1987. Amphetamine impairs the discriminative performance of rats with dorsal noradrenergic bundle lesions on a 5-choice serial reaction time task: new evidence for central dopaminergic-noradrenergic interactions. Psychopharmacology (Berl) 91: $458-466$.

de Quervain DJ, Aerni A, Roozendaal B. 2007. Preventive effect of $\beta$-adrenoceptor blockade on glucocorticoid-induced memory retrieval deficits. Am J Psychiatry 164: 967-969.

Dolder CR, Davis LN, McKinsey J. 2010. Use of psychostimulants in patients with dementia. Ann Pharmacother 44: 1624-1632.

Dommett EJ, Henderson EL, Westwell MS, Greenfield SA. 2008. Methylphenidate amplifies long-term plasticity in the hippocampus via noradrenergic mechanisms. Learn Mem 15: 580-586.

Eagle DM, Tufft MR, Goodchild HL, Robbins TW. 2007. Differential effects of modafinil and methylphenidate on stop-signal reaction time task performance in the rat, and interactions with the dopamine receptor antagonist cis-flupenthixol. Psychopharmacology (Berl) 192: 193-206.

Ersche KD, Clark L, London M, Robbins TW, Sahakian BJ. 2006. Profile of executive and memory function associated with amphetamine and opiate dependence. Neuropsychopharmacology 31: 1036-1047.

Galizio M, McKinney P, Cerutti DT, Pitts RC. 2009. Effects of MDMA, methamphetamine and methylphenidate on repeated acquisition and performance in rats. Pharmacol Biochem Behav 94: 305-311.

Garcia VA, Souza de Freitas B, Busato SB, D'Avila Portal BC, Piazza FC, Schroder N. 2013. Differential effects of modafinil on memory in naive and memory-impaired rats. Neuropharmacology 75: 304-311.

Heyser CJ, Pelletier M, Ferris JS. 2004. The effects of methylphenidate on novel object exploration in weanling and periadolescent rats. Ann NY Acad Sci 1021: 465-469.

Horner AE, Heath CJ, Hvoslef-Eide M, Kent BA, Kim CH, Nilsson SR, Alsio J, Oomen CA, Holmes A, Saksida LM, et al. 2013. The touchscreen operant platform for testing learning and memory in rats and mice. Nat Protoc 8: $1961-1984$.

Josey M, Brigman JL. 2015. Loss of hippocampal function impairs pattern separation on a mouse touch-screen operant paradigm. Neurobiol Learn Mem 125: 85-92.

Keri S, Szamosi A, Benedek G, Kelemen O. 2012. How does the hippocampal formation mediate memory for stimuli processed by the magnocellular and parvocellular visual pathways? Evidence from the comparison of schizophrenia and amnestic mild cognitive impairment (aMCI). Neuropsychologia 50: 3193-3199.

Kim CH, Heath CJ, Kent BA, Bussey TJ, Saksida LM. 2015. The role of the dorsal hippocampus in two versions of the touchscreen automated paired associates learning (PAL) task for mice. Psychopharmacology (Berl) 232: $3899-3910$.
Kuczenski R, Segal DS. 1997. Effects of methylphenidate on extracellular dopamine, serotonin, and norepinephrine: comparison with amphetamine. J Neurochem 68: 2032-2037.

Mar AC, Horner AE, Nilsson SR, Alsio J, Kent BA, Kim CH, Holmes A, Saksida LM, Bussey TJ. 2013. The touchscreen operant platform for assessing executive function in rats and mice. Nat Protoc 8: 1985-2005.

McCabe SE, Knight JR, Teter CJ, Wechsler H. 2005. Non-medical use of prescription stimulants among US college students: prevalence and correlates from a national survey. Addiction 100: 96-106.

Milstein JA, Dalley JW, Robbins TW. 2010. Methylphenidate-induced impulsivity: pharmacological antagonism by $\beta$-adrenoreceptor blockade. J Psychopharmacol 24: 309-321.

Minzenberg MJ, Carter CS. 2008. Modafinil: a review of neurochemical actions and effects on cognition. Neuropsychopharmacology 33: 1477-1502.

Morgan RE, Crowley JM, Smith RH, LaRoche RB, Dopheide MM. 2007. Modafinil improves attention, inhibitory control, and reaction time in healthy, middle-aged rats. Pharmacol Biochem Behav 86: 531-541.

Muller U, Rowe JB, Rittman T, Lewis C, Robbins TW, Sahakian BJ. 2013 Effects of modafinil on non-verbal cognition, task enjoyment and creative thinking in healthy volunteers. Neuropharmacology 64: 490-495.

Murschall A, Hauber W. 2005. Effects of a systemic AMPA/KA and NMDA receptor blockade on Pavlovian-instrumental transfer. Psychopharmacology (Berl) 182: 290-296.

Repantis D, Schlattmann P, Laisney O, Heuser I. 2010. Modafinil and methylphenidate for neuroenhancement in healthy individuals: a systematic review. Pharmacol Res 62: 187-206.

Rostron CL, Kaplan E, Gaeta V, Nigriello R, Dommett EJ. 2013. The effects of methylphenidate on cognitive performance of healthy male rats. Front Neurosci 7: 97.

Sara SJ, Deweer B. 1982. Memory retrieval enhanced by amphetamine after a long retention interval. Behav Neural Biol 36: 146-160.

Schutsky K, Ouyang M, Castelino CB, Zhang L, Thomas SA. 2011. Stress and glucocorticoids impair memory retrieval via $\beta 2$-adrenergic, $\mathrm{Gi} /$ o-coupled suppression of cAMP signaling. J Neurosci 31: 14172-14181.

Shuman T, Wood SC, Anagnostaras SG. 2009. Modafinil and memory: effects of modafinil on Morris water maze learning and Pavlovian fear conditioning. Behav Neurosci 123: 257-266.

Sommer S, Danysz W, Russ H, Valastro B, Flik G, Hauber W. 2014. The dopamine reuptake inhibitor MRZ-9547 increases progressive ratio responding in rats. Int J Neuropsychopharmacol 17: 2045-2056.

Taffe MA, Weed MR, Gutierrez T, Davis SA, Gold LH. 2002. Differential muscarinic and NMDA contributions to visuo-spatial paired-associate learning in rhesus monkeys. Psychopharmacology (Berl) 160: 253-262.

Talpos J, Steckler T. 2013. Touching on translation. Cell Tissue Res 354: 297-308.

Talpos JC, Winters BD, Dias R, Saksida LM, Bussey TJ. 2009. A novel touchscreen-automated paired-associate learning (PAL) task sensitive to pharmacological manipulation of the hippocampus: a translational rodent model of cognitive impairments in neurodegenerative disease. Psychopharmacology (Berl) 205: 157-168.

Talpos JC, Fletcher AC, Circelli C, Tricklebank MD, Dix SL. 2012. The pharmacological sensitivity of a touchscreen-based visual discrimination task in the rat using simple and perceptually challenging stimuli. Psychopharmacology (Berl) 221: 437-449.

Talpos JC, Aerts N, Fellini L, Steckler T. 2014. A touch-screen based paired-associates learning (PAL) task for the rat may provide a translatable pharmacological model of human cognitive impairment. Pharmacol Biochem Behav 122: 97-106.

Talpos JC, Aerts N, Waddell J, Steckler T. 2015. MK-801 and amphetamine result in dissociable profiles of cognitive impairment in a rodent paired associates learning task with relevance for schizophrenia. Psychopharmacology (Berl) 232: 3911-3920.

Turner DC, Robbins TW, Clark L, Aron AR, Dowson J, Sahakian BJ. 2003a. Cognitive enhancing effects of modafinil in healthy volunteers. Psychopharmacology (Berl) 165: 260-269.

Turner DC, Robbins TW, Clark L, Aron AR, Dowson J, Sahakian BJ. 2003b. Relative lack of cognitive effects of methylphenidate in elderly male volunteers. Psychopharmacology (Berl) 168: 455-464.

Waters KA, Burnham KE, O'Connor D, Dawson GR, Dias R. 2005. Assessment of modafinil on attentional processes in a five-choice serial reaction time test in the rat. J Psychopharmacol 19: 149-158.

Zhu N, Weedon J, Dow-Edwards DL. 2007. Oral methylphenidate improves spatial learning and memory in pre- and periadolescent rats. Behav Neurosci 121: 1272-1279.

Received September 25, 2015; accepted in revised form May 9, 2016 


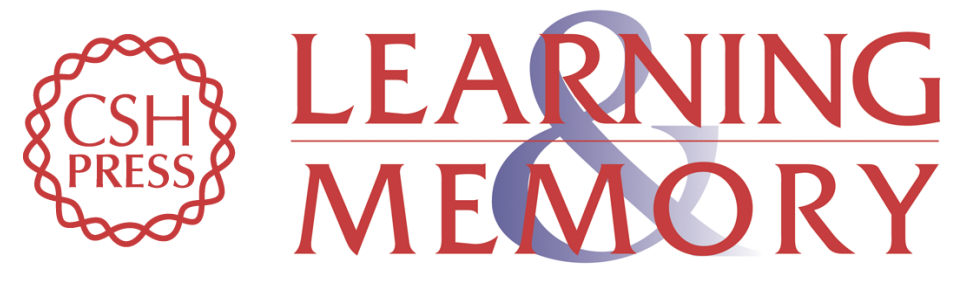

\section{Stimulant drug effects on touchscreen automated paired-associates learning (PAL) in rats}

Corinna Roschlau, Angeline Votteler and Wolfgang Hauber

Learn. Mem. 2016, 23:

Access the most recent version at doi:10.1101/Im.040345.115

\section{Supplemental http://learnmem.cshlp.org/content/suppl/2016/07/12/23.8.422.DC1 Material}

References This article cites 46 articles, 2 of which can be accessed free at: http://learnmem.cshlp.org/content/23/8/422.full.html\#ref-list-1

Creative This article is distributed exclusively by Cold Spring Harbor Laboratory Press for the Commons first 12 months after the full-issue publication date (see

License http://learnmem.cshlp.org/site/misc/terms.xhtml). After 12 months, it is available under a Creative Commons License (Attribution-NonCommercial 4.0 International), as described at http://creativecommons.org/licenses/by-nc/4.0/.

Email Alerting Receive free email alerts when new articles cite this article - sign up in the box at the Service top right corner of the article or click here. 